\title{
ANALISIS POTENSI SUMBERDAYA AIR DI DAS PAGUYAMAN
}

\author{
Ikrima Staddal \\ Program Studi Mesin dan Peralatan Pertanian, Politeknik Gorontalo \\ Email: iqrimha_st@poligon.ac.id
}

\begin{abstract}
ABSTRAK
Kebutuhan air terus meningkat seiring pertumbuhan penduduk sedangkan air yang tersedia tidak selalu sejalan antara kebutuhannya menurut volume, tempat, waktu dan kualitasnya. Penelitian ini bertujuan untuk melihat neraca penggunaan air di DAS Paguyaman berdasarkan penggunaannya. Metode penelitian dilakukan dengan beberapa tahapan, tahapan pertama menghitung laju pertumbuhan penduduk menggunakan model kurva linear. Kedua, menghitung kebutuhan air domestik berdasarkan banyaknya jumlah penduduk dan melakukan proyeksi kebutuhan air domestik selama 20 tahun. Ketiga, menghitung kebutuhan air non domestik, industri dan irigasi berdasarkan penggunaan air dari dirjen karya cipta dinas pekerjaan umum. Hasil penelitian memperlihatkan bahwa penggunaan air pada sektor domestik, Kecamatan Wonosari, Dulupi dan Mootilango mempunyai kebutuhan air paling banyak sebesar $0.01 \mathrm{~m}^{3} / \mathrm{dt}, 0.02 \mathrm{~m}^{3} / \mathrm{dt}$ dan $0.01 \mathrm{~m}^{3} / \mathrm{dt}$. Kebutuhan air pada pabrik gula dan pabrik skala kecil membutuhkan air sebesar $0.025 \mathrm{~m}^{3} / \mathrm{dt}$ atau dalam dan $0.033 \mathrm{~m}^{3} / \mathrm{dt}$ pada pabrik skala kecil. Kebutuhan air irigasi sebesar $17.33 \mathrm{~m}^{3} / \mathrm{dtk}$ atau 546 juta $\mathrm{m}^{3} / \mathrm{dt}$ dengan luasan daerah irigasi $15.488 \mathrm{Ha}$. Kebutuhan air di DAS Paguyaman paling banyak dimanfaatkan pada sektor irigasi, sektor domestik, non domestik dan industri. Hasil analisis neraca air didapatkan bahwa total kebutuhan air di DAS Paguyaman dalam kurun waktu 20 tahun (tahun 2017-2037) mengalami defisit atau kekurangan air. Apabila dilakukan pemeliharaan dan pengelolaan air dengan baik, maka DAS Paguyaman akan terpenuhi kebutuhan airnya dan pada tahun 2032 sampai tahun 2027 akan mengalami surplus atau air berlebih.
\end{abstract}

Kata Kunci: DAS Paguyaman, Neraca Air, Kebutuhan Air, Domestik, Irigasi

\section{ABSTRACT}

Water demand continues to increase with population growth while water availability decreases based on volume, place, time, and quality. This study aims to observe the water balance in the Paguyaman Watershed based on its use. The research method was carried out with several stages, the first stage calculating the rate of population growth using a linear curve model. Second, calculate domestic water needs based on the number of population and make projections of domestic water needs for 20 years. Third, calculate non-domestic, industrial, and irrigation water needs based on water use from the Director-General of Public Works Department of Public Works. The results showed that the use of water in the domestic sector, Wonosari, Dulupi, and Mootilango Districts had the most water requirements of $0.01 \mathrm{~m} 3 / \mathrm{s}, 0.02 \mathrm{m3} / \mathrm{s}$ and $0.01 \mathrm{~m} 3 / \mathrm{s}$. Water requirements in a sugar factory at $0.025 \mathrm{~m} 3 / \mathrm{s}$ and $0.033 \mathrm{~m} 3 / \mathrm{s}$ at small scale factories. Irrigation water needs of $17.33 \mathrm{~m} 3 / \mathrm{s}$ or 546 million $\mathrm{m3} / \mathrm{s}$ with an irrigation area of 15,488 Ha. Water demand in the Paguyaman Watershed is most widely used in the irrigation sector, the domestic, non-domestic, and industrial sectors. The results of the water balance analysis found that the total water demand in the Paguyaman Watershed within a period of 20 years (in 2017-2037) experienced a deficit or lack of water. If water maintenance and management are carried out properly, the Paguyaman Watershed will be fulfilled and in 2032 to 2027 will experience a surplus or excess water.

\section{Keywords: Paguyaman Watershed, Water Balance, Water Demand, Domestic, Irrigation}

\section{PENDAHULUAN}

Sumber daya air merupakan suatu sumber daya berupa air yang sangat berguna untuk kebutuhan manusia. Kebutuhan air ini bertujuan untuk pertanian, industri, domestik maupun non domestik. Tingkat kebutuhan dasar sumberdaya air berkisar 20-30 liter/jiwa/hari. Sedangkan kebutuhan air untuk industri dapat dikategorikan berdasarkan banyaknya pemakaian, masing-masing untuk industri besar berkisar 151-350 $\mathrm{m}^{3} /$ hari, industri

Menurut Chay Asdak (2010) DAS adalah suatu wilayah daratan yang secara topografik dibatasi oleh punggung-punggung gunung yang menampung dan menyimpan air hujan untuk kemudian menyalurkan ke laut melalui sungai sedang berkisar 51-151 $\mathrm{m}^{3} /$ hari, dan industri kecil berkisar 5-50 $\mathrm{m}^{3} /$ hari (Purwanto, 2007). Adapun kebutuhan untuk pertanian adalah besarnya evapotranspirasi yang dibutuhkan setiap tanaman untuk tumbuh dan berkembang dari pengolahan tanah sampai panen atau selama periode tumbuh (Mustafil, 2014), sehingga dalam penelitian ini hanya dijelaskan potensi air untuk kebutuhan air pada industri, irigasi, domestik dan non domestik utama. Wilayah DAS dibagi ke dalam tiga bagian yaitu hulu, tengah dan hilir, sehingga dalam satu DAS bisa terdiri dari beberapa kabupaten/kota bahkan provinsi. DAS Paguyaman terletak di tiga kabupaten, yaitu Kabupaten Gorontalo, Kabupaten 
Boalemo dan Kabupaten Pohuwato. DAS Paguyaman mempunyai luasan $240.356 \mathrm{Ha}$ yang merupakan DAS terbesar kedua di Provinsi Gorontalo. DAS paguyaman memilki peran yang sangat vital dalam menyangga kehidupan masyarakat di tiga kabupaten tersebut. DAS Paguyaman menjadi penyedia air baku untuk berbagai kebutuhan seperti PDAM, irigasi, industri, debit minimum 0,84 $\mathrm{m}^{3} / \mathrm{s}$ (BWS II, 2016)

Penelitian ini bertujuan untuk melihat kebutuhan air di DAS Paguyaman berdasarkan sektor domestik, non domestik, industri dan irigasi

\section{METODE PENELITIAN}

\subsection{Waktu dan Tempat}

Penelitian ini laksanakan di DAS Paguyaman yang berada di Kabupaten Gorontalo, Kabupaten Boalemo dan Kabupaten Pohuwato. Penelitian ini dilakukan selama 3 bulan, mulai dari Bulan Desember 2019 sampai dengan Bulan Februari 2020. Gambar 1 memperlihatkan lokasi penelitian.

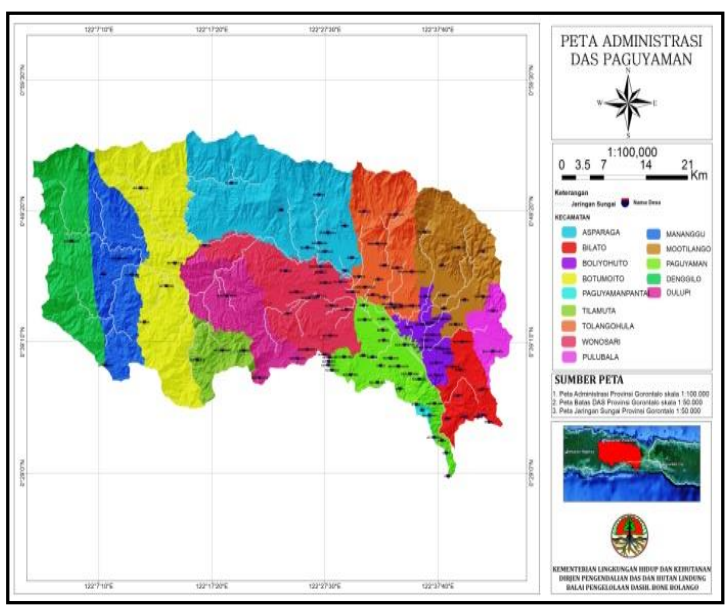

Gambar 1. Lokasi penelitian di DAS Paguyaman

\subsection{Metode Pengambilan Data}

Metode pengambilan data dilakukan melalui dua tahapan yaitu pengambilan data primer dan data sekunder. Data primer berupa pengukuran secara langsung di lokasi penelitian berupa pengukuran debit aliran sungai dan kualitas air sungai, sedangkan data sekunder berupa wawancara dan studi pustaka.

\subsection{Metode Pengolahan Data}

Beberapa pengolahan data dilakukan dengan cara sebagai berikut:

1. Menghitung neraca air di DAS Paguyaman berdasarkan kebutuhan penduduknya yang pemukiman dan kebutuhan lainnya (BPDASHL Bone Bolango, 2019)

Saat ini DAS Paguyaman termasuk dalam DAS kritis yang harus segera dipulihkan. Kondisi ini disebabkan tingginya erosi dan sedimentasi. Hal ini berakibat semakin berkurangnya debit aliran sungai di Sungai Paguyaman yang rata-rata memiliki

didapatkan dengan melihat laju pertumbuhan penduduk. Laju pertumbuhan penduduk dihitung menggunkan model kurva linier yang selanjutnya digunakan untuk mengetahui kebutuhan air di masa mendatang (Muljarijadi, 2017)

$$
P_{n}=P_{n-1}+r=P_{0}+(n-1) r+r=P_{0}+n . r
$$

Keterangan:

$r \quad$ = Laju pertumbuhan penduduk

$\mathrm{P}_{0}=$ Jumlah Penduduk Pada Tahun dasar

$\mathrm{n}=$ Periode tahun

2. Menghitung kebutuhan air domestik di DAS Paguyaman berdasarkan kebutuhan per kecamatan. Kebutuhan air domestik dihitung berdasarkan ketentuan dari SNI (domestik=120 ltr/penghuni/hari)

3. Menghitung kebutuhan air non domestik di DAS Paguyaman berdasarkan kebutuhan dari sektor pariwisata dan perniagaan

4. Menghitung kebutuhan air Pabrik di DAS Paguyaman dilakukan berdasarkan kebutuhan air dari industri pabrik gula. Hai ini dikarenakan pabrik gula merupakan industri yang mendominasi di DAS Paguyaman

5. Menghitung kebutuhan air irigasi di DAS Paguyaman dilakukan berdasarkan pengukuran debit sungai selanjutnya diproyeksikan berdasarkan data daerah irigasi dalam dokumen pola Pengelolaan Sumber Daya Air DAS Paguyaman Tahun 2012 dan data Peraturan Menteri Pekerjaan Umum Dan Perumahan Rakyat .

\section{HASIL DAN PEMBAHASAN}

\subsection{Neraca Air DAS Paguyaman}

Kebutuhan air domestik di DAS Paguyaman diperoleh dari layanan PDAM dan pengambilan air tanah, sedangkan kebutuhan air industri disuplai dari Sungai Paguyaman dan anak-anak sungainya.

Kebutuhan air di DAS Paguyaman dilakukan berdasarkan data penduduk Tahun 2016. Proyeksi jumlah penduduk untuk 20 (dua puluh) tahun ke depan ditentukan berdasarkan laju pertumbuhan penduduk Tahun 2016-2037. 
Tabel 1. Neraca air permukaan DAS paguyaman

\begin{tabular}{|c|c|c|c|c|c|c|c|}
\hline \multirow{2}{*}{ No } & \multirow{2}{*}{ Kabupaten } & \multicolumn{6}{|c|}{ Penduduk (jiwa) } \\
\hline & & 2016 & 2017 & 2022 & 2027 & 2032 & 2037 \\
\hline $\mathbf{A}$ & BOALEMO & & & & & & \\
\hline 1 & Mananggu & 13.466 & 13.922 & 16.205 & 18.487 & 20.770 & 23.052 \\
\hline 2 & Tilamuta & 30.364 & 31.324 & 36.121 & 40.919 & 45.716 & 50.514 \\
\hline 3 & Botumoito & 15.451 & 15.901 & 18.149 & 20.397 & 22.645 & 24.893 \\
\hline 4 & Dulupi & 17.043 & 17.571 & 20.213 & 22.855 & 25.496 & 28.138 \\
\hline 5 & Paguyaman & 32.271 & 33.375 & 38.893 & 44.411 & 49.930 & 55.448 \\
\hline 6 & Paguyaman Pantai & 8.242 & 8.530 & 9.973 & 11.415 & 12.858 & 14.300 \\
\hline 7 & Wonosari & 26.422 & 27.865 & 35.078 & 42.291 & 49.504 & 56.717 \\
\hline B & GORONTALO & & & & & & \\
\hline 1 & Tolangohula & 22.498 & 22.898 & 24.901 & 26.903 & 28.905 & 30.908 \\
\hline 2 & Asparaga & 13.775 & 14.020 & 15.246 & 16.472 & 17.698 & 18.924 \\
\hline 3 & Pulubala & 6.263 & 6.347 & 6.765 & 7.184 & 7.602 & 8.021 \\
\hline 4 & Boliyohuto & 16.688 & 17.092 & 19.115 & 21.137 & 23.159 & 25.181 \\
\hline 5 & Bilato & 5.974 & 6.119 & 6.843 & 7.567 & 8.291 & 9.015 \\
\hline 6 & Mootilango & 19.690 & 20.158 & 22.498 & 24.838 & 27.179 & 29.519 \\
\hline $\mathrm{C}$ & POHUWATO & & & & & & \\
\hline 1 & Dengilo & 4.590 & 4.701 & 5.256 & 5.811 & 6.367 & 6.922 \\
\hline & Total & 232.737 & 239.824 & 275.255 & 310.689 & 346.121 & 381.552 \\
\hline
\end{tabular}

Berdasarkan Tabel 1 tentang proyeksi penduduk di atas, jumlah penduduk di DAS Paguyaman pada Tahun 2037 berjumlah \pm 381.522 jiwa, dimana komposisi jumlah penduduk terbesar berada di Kecamatan Wonosari, yaitu 56.717 jiwa
$(13,97 \%)$. Sehingga proyeksi kebutuhan air domestik dan non domestik dapat dilihat pada Tabel 2 dan Tabel 3.

Tabel 2. Proyeksi Kebutuhan Air Domestik

\begin{tabular}{|c|c|c|c|c|c|c|c|}
\hline \multirow{2}{*}{ No. } & \multirow{2}{*}{ KECAMATAN } & \multicolumn{6}{|c|}{ Kebutuhan Air $\left(\mathbf{m}^{3} / \mathrm{dt}\right)$} \\
\hline & & 2016 & 2017 & 2022 & 2027 & 2032 & 2037 \\
\hline A & BOALEMO & & & & & & \\
\hline 1 & Mananggu & 0.019 & 0.019 & 0.023 & 0.026 & 0.029 & 0.032 \\
\hline 2 & Tilamuta & 0.042 & 0.044 & 0.050 & 0.057 & 0.063 & 0.070 \\
\hline 3 & Botumoito & 0.021 & 0.022 & 0.025 & 0.028 & 0.031 & 0.035 \\
\hline 4 & Dulupi & 0.024 & 0.024 & 0.028 & 0.032 & 0.035 & 0.039 \\
\hline 5 & Paguyaman & 0.045 & 0.046 & 0.054 & 0.062 & 0.069 & 0.077 \\
\hline 6 & Paguyaman Pantai & 0.011 & 0.012 & 0.014 & 0.016 & 0.018 & 0.020 \\
\hline 7 & Wonosari & 0.037 & 0.039 & 0.049 & 0.059 & 0.069 & 0.079 \\
\hline $\mathbf{B}$ & GORONTALO & & & & & & \\
\hline 1 & Tolangohula & 0.031 & 0.032 & 0.035 & 0.037 & 0.040 & 0.043 \\
\hline 2 & Asparaga & 0.019 & 0.019 & 0.021 & 0.023 & 0.025 & 0.026 \\
\hline 3 & Pulubala & 0.009 & 0.009 & 0.009 & 0.010 & 0.011 & 0.011 \\
\hline 4 & Boliyohuto & 0.023 & 0.024 & 0.027 & 0.029 & 0.032 & 0.035 \\
\hline 5 & Bilato & 0.008 & 0.008 & 0.010 & 0.011 & 0.012 & 0.013 \\
\hline 6 & Mootilango & 0.027 & 0.028 & 0.031 & 0.034 & 0.038 & 0.041 \\
\hline $\mathrm{C}$ & POHUWATO & & & & & & \\
\hline 1 & Dengilo & 0.006 & 0.007 & 0.007 & 0.008 & 0.009 & 0.010 \\
\hline & TOTAL & 0.322 & 0.333 & 0.383 & 0.432 & 0.481 & 0.531 \\
\hline
\end{tabular}


Proyeksi air berdasarkan kebutuhan air domestik terlihat bahwa total kebutuhan air di DAS Paguyaman pada tahun 2016 sebesar 0,322 m3/dtk. Kecamatan Wonosari $\left(0,079 \mathrm{~m}^{3} / \mathrm{dt}\right)$, Paguyaman $\left(0,077 \mathrm{~m}^{3} / \mathrm{dt}\right)$ dan Tilamuta $\left(0,070 \mathrm{~m}^{3} / \mathrm{dt}\right)$ mempunyai kebutuhan air paling besar, hal ini dikarenakan kecamatan tersebut memiliki jumlah penduduk yang paling banyak dibandingkan kecamatan lainnya.
Kebutuhan air non domestik adalah kebutuhan air untuk memenuhi sarana-sarana kota, seperti sarana sosial, industri dan niaga. Perkiraan kebutuhan air tersebut tergantung dari jenis kegiatan non domestik tersebut. Kebutuhan air non domestik di DAS Paguyaman diperoleh melalui kriteria perencanaan Ditjen Cipta Karya Dinas Pekerjaan Umum.

Tabel 3. Proyeksi Kebutuhan Air Non Domestik

\begin{tabular}{|l|l|l|l|l|l|l|l|}
\hline \multirow{2}{*}{ No. } & \multirow{2}{*}{ Kecamatan } & \multicolumn{2}{|l|}{ Kebutuhan Air $\left(\mathbf{m}^{\mathbf{3}} / \mathbf{d t}\right)$} \\
\cline { 3 - 8 } & & $\mathbf{2 0 1 6}$ & $\mathbf{2 0 1 7}$ & $\mathbf{2 0 2 2}$ & $\mathbf{2 0 2 7}$ & $\mathbf{2 0 3 2}$ & $\mathbf{2 0 3 7}$ \\
\hline $\mathbf{A}$ & BOALEMO & & & & & & \\
\hline 1 & Mananggu & 0.005 & 0.005 & 0.006 & 0.006 & 0.007 & 0.008 \\
\hline 2 & Tilamuta & 0.011 & 0.011 & 0.013 & 0.014 & 0.016 & 0.018 \\
\hline 3 & Botumoito & 0.005 & 0.006 & 0.006 & 0.007 & 0.008 & 0.009 \\
\hline 4 & Dulupi & 0.006 & 0.006 & 0.007 & 0.008 & 0.009 & 0.01 \\
\hline 5 & Paguyaman & 0.011 & 0.012 & 0.014 & 0.015 & 0.017 & 0.019 \\
\hline 6 & Paguyaman Pantai & 0.003 & 0.003 & 0.003 & 0.004 & 0.004 & 0.005 \\
\hline 7 & Wonosari & 0.009 & 0.01 & 0.012 & 0.015 & 0.017 & 0.02 \\
\hline
\end{tabular}

\begin{tabular}{|l|l|l|l|l|l|l|l|}
$\mathbf{B}$ & GORONTALO & & & & & \\
\hline 1 & Tolangohula & 0.008 & 0.008 & 0.009 & 0.009 & 0.01 & 0.011 \\
\hline 2 & Asparaga & 0.005 & 0.005 & 0.005 & 0.006 & 0.006 & 0.007 \\
\hline 3 & Pulubala & 0.002 & 0.002 & 0.002 & 0.002 & 0.003 & 0.003 \\
\hline 4 & Boliyohuto & 0.006 & 0.006 & 0.007 & 0.007 & 0.008 & 0.009 \\
\hline 5 & Bilato & 0.002 & 0.002 & 0.002 & 0.003 & 0.003 & 0.003 \\
\hline 6 & Mootilango & 0.007 & 0.007 & 0.008 & 0.009 & 0.009 & 0.01 \\
\hline C & POHUWATO & & & & & & \\
\hline 1 & Dengilo & 0.002 & 0.002 & 0.002 & 0.002 & 0.002 & 0.002 \\
\hline TOTAL & & $\mathbf{0 . 0 8 2}$ & $\mathbf{0 . 0 8 5}$ & $\mathbf{0 . 0 9 6}$ & $\mathbf{0 . 1 0 7}$ & $\mathbf{0 . 1 1 9}$ & $\mathbf{0 . 1 3 4}$ \\
\hline
\end{tabular}

Kebutuhan air non domestik di DAS Paguyaman sebesar $0.082 \mathrm{~m} 3 / \mathrm{dtk}$. Hal ini lebih sedikit jika dibandingkan dengan kebutuhan air domestik. Analisis kebutuhan air non domestik dilakukan hanya pada sektor sekolah dan perkantoran daerah. Kecamatan Tilamuta, Paguyaman dan Wonosari memiliki kebutuhan air non domestik yang paling banyak karena jumlah sekolah dan kantor daerah di kecamatan tersebut paling banyak

\subsection{Kebututuhan Air Industri}

Industri yang terdapat di DAS Paguyaman adalah industri kecil/rumah tangga dan pabrik gula. Kebutuhan air pabrik gula dianalisa berdasarkan jumlah produksi gula yang dihasilkan. Untuk setiap ton produksi gula, memerlukan $\pm 20 \mathrm{~m}^{3}$ air dengan rincian sebagaimana terdapat pada Tabel 4.
Tabel 4. Kebutuhan Air Pabrik Gula di DAS Paguyaman

\begin{tabular}{|c|l|c|}
\hline No & Tipe Air & $\begin{array}{c}\text { Konsumsi } \\
(\mathbf{L} \text { air/ton } \\
\text { Gula })\end{array}$ \\
\hline 1 & Flume water & $500-8.000$ \\
\hline 2 & Washing water & $\begin{array}{c}1.500- \\
2.500\end{array}$ \\
\hline 3 & $\begin{array}{l}\text { Earth transport } \\
\text { water }\end{array}$ & $150-250$ \\
\hline 4 & Ekstraksi jus tebu & $300-400$ \\
\hline 5 & Purifikasi jus & 120 \\
\hline 6 & Kondensasi & $\begin{array}{c}4.000- \\
6.000\end{array}$ \\
\hline 7 & Stream generation & 40 \\
\hline 8 & Cleaning & 20 \\
\hline 9 & Pertukaran ion & $50-130$ \\
\hline 10 & $\begin{array}{l}\text { Pendinginan dan } \\
\text { pemompaan }\end{array}$ & $400-5.000$ \\
\hline & Total & $\begin{array}{c}\mathbf{1 1 . 5 8 0}- \\
\mathbf{2 2 . 4 6 0}\end{array}$ \\
\hline
\end{tabular}


Kebutuhan air untuk industri kecil /rumah tangga diasumsikan sebesar 5\% dari kebutuhan domestik (SNI 19-6728.1 Tahun 2002 tentang Penyusunan Neraca Sumber Daya Air
Spasial). Adapun proyeksi kebutuhan air untuk industri dilakukan berdasarkan trend pertumbuhan industri dan jumlah produksi industri di DAS Paguyaman.

Tabel 5.Proyeksi Kebutuhan Air Industri

\begin{tabular}{|c|c|c|c|c|c|c|c|}
\hline \multirow{2}{*}{ Tahun } & \multicolumn{6}{|c|}{ Industri Gula } & \multicolumn{2}{c|}{ Lain-lain } & \multicolumn{2}{c|}{ Total } \\
\cline { 2 - 7 } & Produksi & \multicolumn{4}{|c|}{ Kebutuhan Air } \\
\cline { 2 - 7 } & ton/tahun & $\mathbf{m}^{\mathbf{3} / \mathbf{t o n}}$ & $\mathbf{m}^{\mathbf{3}}$ & $\mathbf{m}^{\mathbf{3}} / \mathbf{d t}$ & $\mathbf{m}^{\mathbf{3}} / \mathbf{d t}$ & $\mathbf{m}^{\mathbf{3}} / \mathbf{d t}$ \\
\hline 2010 & 27,400 & 20 & 548 & 0,017 & - & 0,017 \\
\hline 2011 & 32,200 & 20 & 644 & 0,020 & - & 0,020 \\
\hline 2012 & 31,800 & 20 & 636 & 0,020 & - & 0,020 \\
\hline 2013 & 39,100 & 20 & 782 & 0,025 & - & 0,025 \\
\hline 2014 & 39,100 & 20 & 782 & 0,025 & - & 0,025 \\
\hline 2016 & 40,000 & 20 & 800 & 0,025 & 0,019 & 0,045 \\
\hline 2017 & 40,000 & 20 & 800 & 0,025 & 0,020 & 0,045 \\
\hline 2022 & 40,000 & 20 & 800 & 0,025 & 0,023 & 0,048 \\
\hline 2027 & 40,000 & 20 & 800 & 0,025 & 0,026 & 0,052 \\
\hline 2032 & 40,000 & 20 & 800 & 0,025 & 0,029 & 0,055 \\
\hline 2037 & 40,000 & 20 & 800 & 0,025 & 0,033 & 0,058 \\
\hline
\end{tabular}

\subsection{Kebutuhan Air Irigasi}

Proyeksi daerah irigasi diasumsikan berdasarkan data daerah irigasi dalam dokumen pola Pengelolaan Sumber Daya Air DAS Paguyaman Tahun 2012 dan data Peraturan Menteri Pekerjaan Umum Dan Perumahan Rakyat Nomor 14/PRT/M/2015 serta diasumsikan sampai Tahun 2019 tidak ada penambahan areal irigasi baru, maka diperoleh rata-rata kebutuhan air irigasi DAS Paguyaman pada Tahun 2019 (dengan asumsi kebutuhan air untuk sawah adalah 1,11 1/dt/ha) adalah sebesar $17.37 \mathrm{~m}^{3} / \mathrm{dt}$ dengan daerah irigasi seluas $15.549 \mathrm{Ha}$.

Dalam rangka mendukung peningkatan ketahanan pangan terutama beras yang didukung potensi air permukaan dan pemanfaatan ketersediaan lahan berdasarkan luas baku sawah yang ada di DAS Paguyaman, maka diproyeksikan total daerah irigasi Tahun 2037 mencapai luas 15.588 Ha dengan kebutuhan air irigasi sebesar $17.37 \mathrm{~m} 3 / \mathrm{dt}$. Penambahan lahan irigasi diasumsikan berdasarkan data luas baku sawah yang ada, sehingga sampai tahun 2037 diasumsikan seluruh luas baku yang ada sudah berubah menjadi fungsional. Proyeksi luas daerah irigasi dan kebutuhan air irigasi di DAS Paguyaman dapat dilihat pada Tabel 6.
Tabel 6. Proyeksi luas daerah irigasi dan kebutuhan air irigasi di DAS Paguyaman

\begin{tabular}{|c|c|c|}
\hline Tahun & $\begin{array}{c}\text { Luas DI } \\
\text { (ha) }\end{array}$ & $\begin{array}{c}\text { Kebutuhan Air } \\
\text { (m3/dt) }\end{array}$ \\
\hline 2017 & 15.549 & 17.33 \\
\hline 2022 & 15.588 & 17.37 \\
\hline 2027 & 15.588 & 17.37 \\
\hline 2032 & 15.588 & 17.37 \\
\hline 2037 & 15.588 & 17.37 \\
\hline
\end{tabular}

\subsection{Analisis Neraca Air}

Berdasarkan proyeksi kebutuhan air sampai Tahun 2037, kebutuhan air domestik, non domestik, industri dan irigasi masing-masing sebesar $0,531 \mathrm{~m}^{3} / \mathrm{dt}, 0,134 \mathrm{~m}^{3} / \mathrm{dt}, 0,058 \mathrm{~m}^{3} / \mathrm{dt}$ dan $17.37 \mathrm{~m}^{3} / \mathrm{dt}$ sehingga total kebutuhannya 18.093 $\mathrm{m} 3 / \mathrm{dt}$ atau 570 juta $\mathrm{m}^{3}$. Bila selama 20 (dua puluh) tahun (2017-2037) tidak ada upaya pengembangan sumber daya air di DAS Paguyaman, maka pada Tahun 2037 akan mengalami kekurangan air sebesar \pm 21 juta $\mathrm{m}^{3}$ (-0.67) Sedangkan apabila dalam kurun waktu 20 (dua puluh) tahun (20172037) mendatang dilakukan upaya pengembangan sarana dan prasarana sumber daya air, maka akan terjadi surplus \pm 1.57 juta $\mathrm{m}^{3}(0.05)$. Secara ringkas neraca air DAS Paguyaman Tahun 2017 - 2037 dapat dilihat pada Tabel 4.7. 
Tabel 4.7 Analisis Kebutuhan Air Tahun 2017 - 2037 (m³/dt)

\begin{tabular}{|c|l|c|c|c|c|c|}
\hline \multirow{2}{*}{ No. } & \multirow{2}{*}{ Uraian } & \multicolumn{5}{|c|}{ Tahun } \\
\cline { 3 - 6 } & & 2017 & 2022 & 2027 & 2032 & 2037 \\
\hline 1 & Kebutuhan & & & & & \\
\hline & - Domestik & 0.333 & 0.383 & 0.432 & 0.481 & 0.531 \\
\hline & - Non Domestik & 0.085 & 0.096 & 0.107 & 0.119 & 0.134 \\
\hline & - Industri & 0.045 & 0.048 & 0.052 & 0.055 & 0.058 \\
\hline & - Irigasi & 17.33 & 17.37 & 17.37 & 17.37 & 17.37 \\
\hline 2 & Total Kebutuhan & 17.793 & 17.897 & 17.961 & 18.025 & 18.093 \\
\hline & Ketersediaan*) & 17.42 & 17.42 & 17.42 & 17.42 & 17.42 \\
\hline 3 & Ketersediaan**) & 17.42 & 17.02 & 17.96 & 18.08 & 18.14 \\
\hline & Surplus / Defisit*) & -0.37 & -0.48 & -0.54 & -0.61 & -0.67 \\
\hline
\end{tabular}

\section{Keterangan:}

*) Tanpa upaya pengembangan sumber daya air

**) Dengan upaya pengembangan sumber daya air

\section{KESIMPULAN DAN SARAN}

\subsection{Kesimpulan}

1. Berdasarkan analisis neraca air di DAS Paguyaman didapatkan bahwa Kecamatan Wonosari mempunyai kebutuhan air paling banyak sebesar $0.079 \mathrm{~m}^{3} / \mathrm{dt}$ atau 2.49 juta $\mathrm{m}^{3} / \mathrm{dt}$ dalam setahun

2. Berdasarkan kebutuhan air domestik di DAS Paguyaman didapatkan bahwa Kecamatan Wonosari, Dulupi dan Mootilango mempunyai kebutuhan air paling banyak sebesar $0.01 \mathrm{~m}^{3} / \mathrm{dtk} ; 0.02 \mathrm{~m}^{3} / \mathrm{dtk}$ dan $0.01 \mathrm{~m}^{3} / \mathrm{dtk}$

3. Berdasarkan kebutuhan air industri di DAS Paguyaman dibagi kedalam dua kebutuhan yaitu kebutuhan air untuk pabrik gula sebagai industri paling mendominasi dan industri dalam skala kecil seperti pabrik pembuatan pupuk, benih perikanan dan lainnya

4. Kebutuhan air pabrik gula membutukan $0.025 \mathrm{~m}^{3} / \mathrm{dt}$ atau $788.400 \mathrm{~m}^{3} / \mathrm{dt}$ dalam setahun dan $0.033 \mathrm{~m}^{3} / \mathrm{dt}$ atau 1.04 juta $\mathrm{m}^{3} / \mathrm{dt}$ dalam setahun untuk pabrik skala kecil. Pada pabrik skala kecil didapatkan kebutuhan air yang lebih besar karena diasumsikan pabrik dalam skala kecil akan lebih banyak jumlahnya setiap tahunnya dibandingkan dengan pabrik gula. Hal ini disebabkan perizinan untuk membangun pabrik skala kecil lebih mudah dibandingkan pabrik dengan skala besar, seperti pabrik gula.

5. Kebutuhan air berdasarkan air irigasi dibutuhkan sebesar $17.33 \mathrm{~m}^{3} / \mathrm{dtk}$ atau 546 juta $\mathrm{m}^{3} / \mathrm{dt}$ dengan luasan daerah irigasi (DI) 15.488 $\mathrm{Ha}$.
6. Kebutuhan air di DAS Paguyaman paling banyak diperuntukkan pada sektor irigasi, sektor domestik, non domestik dan industri

7. Hasil analisis neraca air didapatkan total kebutuhan air di DAS Paguyaman dalam kurun waktu 20 tahun (tahun 2017-2037) mengalami defisit atau kekurangan air. Apabila dilakukan pemeliharaan dan pengelolaan air dengan baik maka pada tahun 2027 kebutuhan air di DAS Paguyaman akan terpenuhi dan pada tahun 2032 sampai tahun 2027 akan mengalami surplus atau air berlebih

\subsection{Saran}

Penelitian ini diharapkan bisa dilanjutkan dengan menganalisis kebutuhan air setiap industri yang ada di DAS Paguyaman. Selain kebutuhan air industri, kebutuhan air pertanian juga perlu dilakukan dikarena sebagian besar penggunaan air di DAS Paguyaman dimanfaatkan untuk sektor irigasi

\section{DAFTAR PUSTAKA}

Asdak, Chay. (2010). Hidrologi dan Pengelolaan Daerah Aliran Air Sungai: Edisi. Revisi Kelima. Yogyakarta: Gadjah Mada University Press Yogyakarta.

[Balai Besar Wilayah Sungai Sulawesi II]. 2019. Buku Debit, Curah Hujan dan Klimatologi Provinsi Gorontalo.

[Balai Pengelolaan Sungai dan Hutan Lindung Bone Bolango ]. 2012. Monitoring dan Evaluasi Kinerja DAS Paguyaman. Provinsi Gorontalo

Muljarijadi, B. (2017) Dinamika Penduduk: Pertumbuhan Penduduk, Fertilitas Mortalitas dan Migrasi. Laporan Kemajuan Penelitian 
Fakultas Ekonomi dan Bisnis, Universitas Padjajaran.

Mustafril, (2014). Analisis Potensi Sumberdaya Air di Daerah Sungai Singkil Menggunakan Model Tangki. Jurnal Rona Teknik Pertanian, Volume 7(1). April 2014

[Pekerjaan Umum Dan Perumahan Rakyat]. 2012. Pengelolaan DAS Paguyaman.. Provinsi Gorontalo

Purwanto, M.Y.J. (2007). Kebutuhan Air Sektoral untuk Pengembangan DAS. Jurnal Agritech, Vol 27, No.2 Juni 2007 